\title{
Integra for penile coverage after traumatic degloving - case report
}

\author{
Vlad Pieptu*, Alexandru Mihai, Nicolae Ghetu \\ Department of Plastic and Reconstructive Surgery, "Grigore T. Popa" University of Medicine and \\ Pharmacy, lasi, Romania
}

\begin{abstract}
Penile soft tissue defects can be caused by tumor excision, trauma, burns, Fournier's gangrene and self-mutilation. Reconstruction of such defects has been achieved through various methods (local or regional flaps, full-thickness or split-thickness skin grafts, skin substitutes). Although no consensus has been reached, it seems that split thickness skin grafts are the method of choice. Penis resurfacing is a delicate procedure, especially in potent men, as it aims normal coverage, sensibility, aesthetic aspect and restoring erectile function with sexual satisfaction. We present a case of traumatic avulsion of the anterior perineum successfully treated using split thickness skin grafts for the testicles and Integra ${ }^{\mathrm{TM}}$ for the penis. The follow-up period was 5 years. Functional result was excellent, the penile skin regaining its elasticity, flexibility and pliability. No urinary problems or erectile dysfunctions were noted. Due to its advantages (skin elasticity, limited hypertrophic scar formation and inhibited myofibroblasts contraction) Integra ${ }^{\mathrm{TM}}$ might be the optimal penile coverage solution.
\end{abstract}

Keywords: integra, penis, resurfacing, degloving, avulsion

\section{Introduction}

Penile soft tissue defects can be caused by tumor excision [1, 2], trauma [3-6], burns, Fournier's gangrene [7] and self-mutilation. Reconstruction of such defects has been achieved through various methods: pedicled fascia lata [8] attached either to the tensor fascia lata flap or an anterolateral thigh flap; full thickness [9-11] skin grafts placed in different ways (helicoidal, longitudinal, transversal); sheets of unmeshed, splitthickness skin grafts [12-15], unexpanded 1:1 mesh grafts [7]; preputium flaps combined with scrotal flaps [5], skin substitutes [16, 17].

Received: November 2014; Accepted after review: December 2014; Published: December 2014

*Corresponding author: Vlad Pieptu, MD, PhD, Department of Plastic and Reconstructive Surgery, "Grigore T Popa" University of Medicine and Pharmacy, 16 Universitatii Str., lasi, Romania.

Email: dr.pieptu@gmail.com
Penis resurfacing is a delicate procedure, especially in potent men, as it aims restoring erectile function, sensibility, aesthetic aspect and sexual satisfaction. It seems that split thickness skin grafts remain the method of choice, although no consensus has been reached. However, a strong psychological component is present in all cases and the final aesthetic outcome is very important for the patients.

\section{Case report}

A 31-year old farmer was admitted to the Emergency Accident Hospital lasi immediately after a traumatic avulsion (chain mechanism) of the anterior perineal skin with degloving of penis and both testicles (Figure 1). A urinary catheter was placed and surgical excision of the non-viable tissue was performed. The resulting defect was covered 24 hours later, 
with split-thickness skin grafts for the testicles and a circumferential $25 \times 10 \mathrm{~cm}$ sheet of Integra $^{\mathrm{TM}}$ (Integra Life Sciences Corporations Plainsboro, New Jersey) for the penile shaft (Figure 2). Tie-over dressings were applied and the penis was immobilized in an erect position with a custom-made device. Careful cleaning of the urethral orifice and urinary catheter was performed twice daily. Dressings covering the penile shaft were changed at 3 days interval, in the Operating Room. Small seroma and hematoma were observed through the silicone layer of Integra ${ }^{\mathrm{TM}}$ and evacuation was performed through needle incisions.

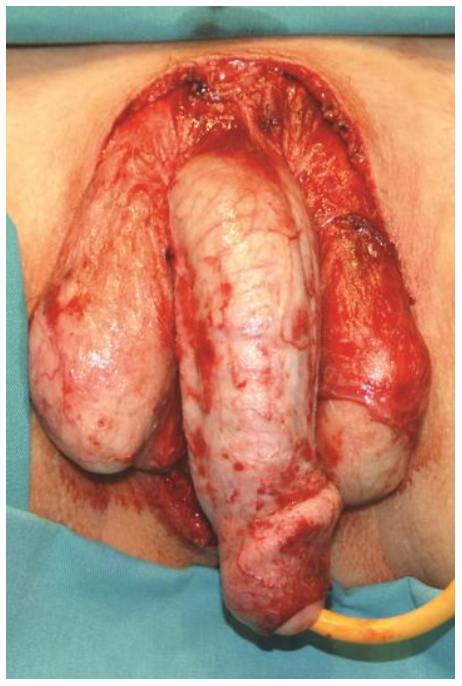

Fig. 1. Aspect upon admission: degloving of the penis and scrotum

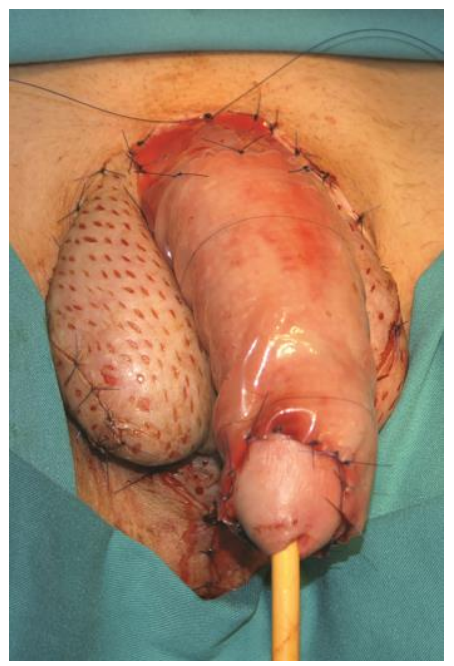

Fig. 2. Coverage (24 hours after admission) with meshed split-thickness skin grafts for testicles and Integra ${ }^{\mathrm{TM}}$ for the penis
At 18 days post-coverage, the neodermis had an orange colour on the totality of its surface.

The silicone membrane was peeled off (Figure 3 ) and a single $25 \times 10 \mathrm{~cm}$ ultra-thin $(1 / 10 \mathrm{~mm})$ split-thickness skin graft was applied. The immobilization, urethral catheter and dressing protocol were maintained for 14 days, ensuring an uneventful healing. The skin graft take was $100 \%$ and the patient was discharged at 33 days after the accident (32 after Integra ${ }^{\mathrm{TM}}$ and 14 after penis grafting).

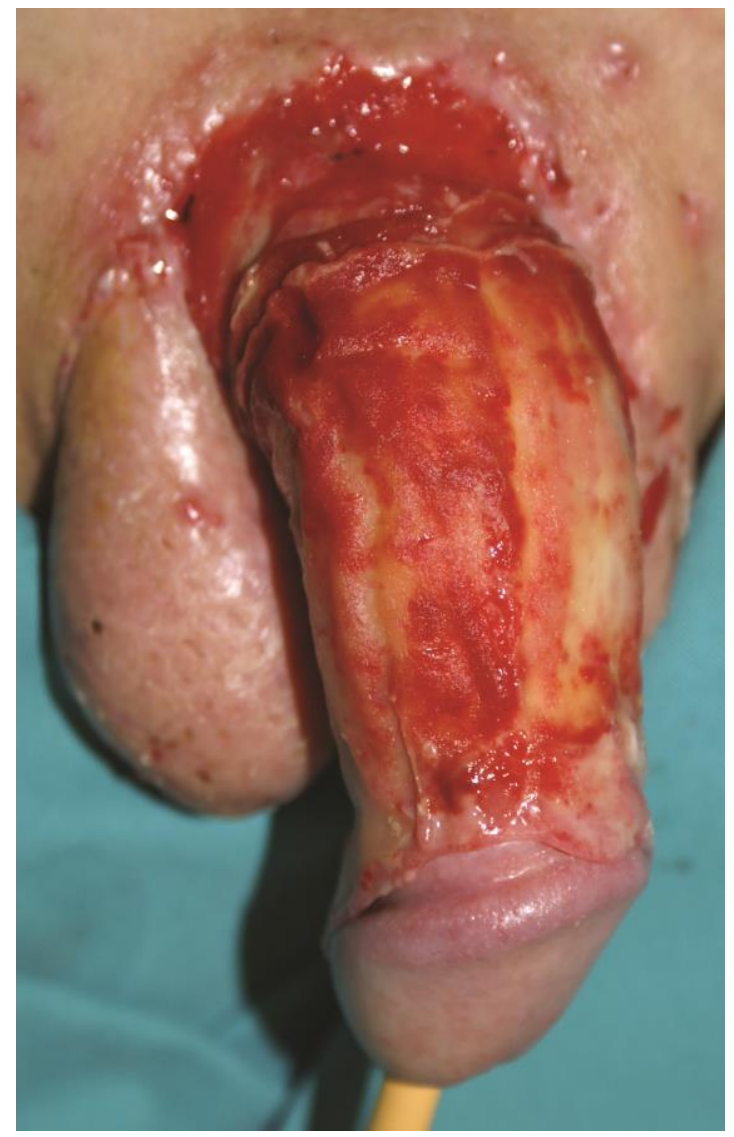

Fig. 3. Day 18 post- Integra ${ }^{\mathrm{TM}}$ : aspect of the neodermis after removal of the silicone layer and before ultra-thin split-thickness skin grafting

After one year, the penile skin regained its elasticity, flexibility and pliability (Figure 4). The follow-up period was 5 years without changing of the external aspect. The patient is very pleased with the functional result (erection and sensibility) and states that he noticed functional improvement up to 15 months after the accident, but refuses pharmacological tests to evaluate skin elasticity during erection. 
The first sexual intercourse was reported 3 months after coverage (4 months after the accident).

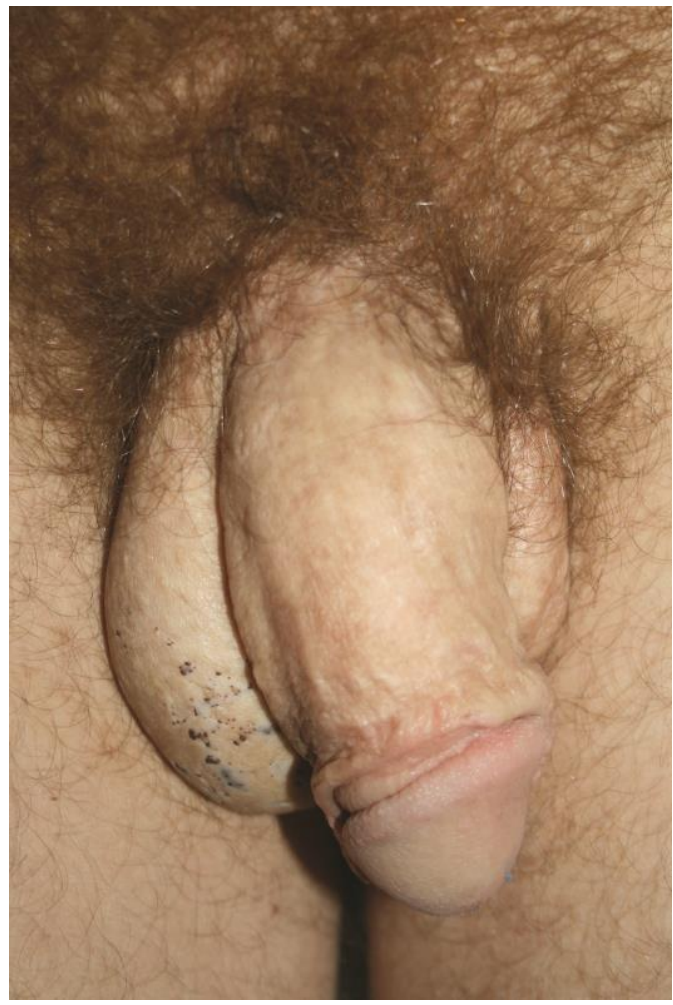

Fig. 4. Aspect at 18 months after trauma. Note good skin pliability, elasticity and overall good aesthetic outcome.

\section{Discussion}

Traumatic avulsion of the male anterior perineum is an impressive psychological trauma for the potent patient. This accident affects mostly farmers working near moving machinery and the typical mechanism [18] was described by Brown in 1957. One pant leg is caught by the moving chain and the patient is pulled in towards the machine by strong rotating forces. The skin is grasped through the pants and degloved in one piece. In most cases, the glans of the penis is left intact while the skin of the penis shaft is pulled off, sometimes alongside with parts or the totality of the scrotum. Medical literature [19] indicates several coverage methods, suggesting that skin grafting results in better outcomes than flaps or other methods.

Integra $^{\mathrm{TM}}$ is a permanent biosynthetic skin substitute. Its bilaminar structure consists of a dermal layer representing a dermal template and an epidermal-like layer acting as a barrier for bacterial invasion and fluid loss. The dermal layer is a porous structure organized as a matrix of cross-linked bovine collagen and shark glycosaminoglycan. After wound coverage, this layer becomes host for the migrating cells originating in the wound bed: endothelial cells, fibroblasts and macrophages. While macrophages degrade the bovine collagen and the endothelial cells form neovessels, the fibroblasts synthetize endogenous collagen. Thus, the dermal layer of Integra ${ }^{\mathrm{TM}}$ is completely replaced in 3 to 6 weeks by a "neodermis" with structure similar to the normal human dermis. The epidermallike layer consists of a synthetic polysiloxane polymer (silicone). Once the neodermis is completely integrated into the wound bed, the silicone layer can be peeled off and replaced with an ultra-thin split thickness skin graft. The result is a "new skin" which is bilayered and belongs to the host organism.

Integra $^{\mathrm{TM}}$ became commercially available in 1997 and widely used especially in the last decade. In reconstructive surgery it was successfully used for coverage in the cervical area [20], breast [21], donor areas [22], over flaps [23, 24], for prefabricated flaps [25], after tumor resection [26], after trauma [27] or in burn surgery [28-30]. Its main advantage is the superior functional and cosmetic outcome, greater flexibility of the resulting skin, due to its thick dermal component. Its biocompatibility with low antigenicity and decreased host inflammatory response limits the granulation tissue and hypertrophic scar formation. The contraction of the myofibroblasts is inhibited [30], thus preventing wound contractions. The main disadvantages of Integra ${ }^{\mathrm{TM}}$ are its susceptibility to infection and the cost (approx. $\left.10 € / \mathrm{cm}^{2}\right)$.

\section{Conclusion}

Considering these advantages, supported by our department's previous experience [31], we advocate that Integra ${ }^{\mathrm{TM}}$ could be a better option for penile coverage than the traditionally accepted skin grafts, the current surgical standard. 
Authors declare no conflicts of interest.

\section{References}

1. Ballaro A, Webster JJ, Ralph D. Penile resurfacing for extensive genital warts. Int $J$ Impot Res 2001; 13(1):47-48.

2. Maruyama S, Ueda K. Scrotal skin replacement for extra mammary Paget's disease - a technique. Brit J Plast Surg 2005; 58:94-96.

3. Conley JJ: A one-stage for the repair of the denuded penis and testicles. N.Y. State $J$ Med 1956; 56:3014.

4. Finical SJ, Arnold PG. Care of the degloved penis and scrotum: A 25-year experience. Plast Reconst Surg 1999; 104:2074-2078.

5. Paraskevas KI, Anagnostou D, Bouris C. An extensive traumatic degloving lesion of the penis. A case report and review of the literature. Int Urol Nephrol 2003; 5(4):523-527.

6. Zanettini LA, Fachinelli A, Fonseca GP. Traumatic degloving lesion of penile and scrotal skin. Int Braz J Urol 2005; 31(3):262-263.

7. Black PC, Friedrich JB, Engrav LH, Wessells $H$. Meshed unexpanded split-thickness skin grafting for reconstruction of penile skin loss. $J$ Urol 2004; 172(3):976-979.

8. Gravvanis Al, Tsoutsos DA, Iconomou TG, Papadopoulos SG. Penile resurfacing with vascularized fascia lata. Microsurgery 2005; 25(6):462-468.

9. McAninch JW. Management of genital skin loss. Urol Clin North Am 1989; 16(2):387-97.

10. Beretta G, Di Giuseppe P, Vaccarella F, Marzotto M, Zanollo A. Post-traumatic penoscrotal avulsion: cosmetic and uroandrologic evaluation after surgical reconstruction. Arch Ital Urol Androl 1994; 66(3):143-149.

11. Cabral L, Teles L, Ferreira LC, Cruzeiro C. Avulsion of the skin of the penis and scrotum. Acta Med Port 1998; 11(2):163-167.

12. Somogyi L, Torok Z, Polyak L, Jilling A. Two cases of traumatic denudation of the penile and scrotal skin. Acta Chir Hung 1987; 28(2):97-103.

13. Netscher DT, Marchi M, Wigoda P. A method for optimizing skin graft healing and outcome of wounds of the penile shaft and scrotum. Ann Plast Surg 1993; 31(5):447-449.

14. Gencosmanoglu R, Bilkay U, Alper M, Gurler T, Cagdas A. Late results of split-grafted penoscrotal avulsion injuries. J Trauma 1995; 39(6):1201-1203.

15. Hrbaty J, Molitor M. Traumatic skin loss from the mail genitalia. Acta Chir Plast 2007; 43(1):17-20.

16. Payne CE, Williams AM, Hart NB. Lotus petal flaps for scrotal reconstruction combined with Integra resurfacing of the penis and anterior abdominal wall following necrotising fasciitis. $J$ Plast Reconstr Aesthet Surg 2009; 62(3):393397.
17. Lakshman S, King SR, Wallace RD. Case report: The use of dermal substitute in the reconstruction of full-thickness burns to the penis, Wounds 2005; 17(6):153-156.

18. Brown JB, Fryer MP. Peno-scrotal skin losses, repaired by implantation and free skin grafting: Report of known normal offspring. Ann Surg 1957; 145(5):656-664.

19. Cavadas Rodriguez P. Massive avulsion of the genital skin in a man. Apropos a case and a review of treatment. Arch Esp Urol 1995; 48(9):952-954

20. Hunt JA, Miosidis E, Haersch P. Initial experience of Integra in the treatment of postburn anterior cervical neck contracture. Brit $J$ Plast Surg 2000; 53:652-658.

21. Palao R, Gomez P, Huguet P. Burned breast reconstructive surgery with Integra dermal regeneration template. Brit J Plast Surg 2003; 56:252-259.

22. Wang JCY, To EWH. Application of dermal substitute (Integra) to donor site defect of forehead flap. Br J Plast Surg 2000; 53(1):70-2.

23. Giovaninni UM, Teot L. Aesthetic complex reconstruction of the lower leg: application of a dermal substitute (Integra) to an adipofascial flap. Br J Plast Surg 2002; 55(2):171-172.

24. Moore $C$, Lee $S$, Hart A, Watson S. Use of Integra to resurface a latissimus dorsi free flap, Br J Plast Surg 2003; 56(1):66-69.

25. Houle JM, Neumeister MW. A prefabricated, tissue-engineered integra free flap. Plast Reconstr Surg 2007; 120(5):1322-1325.

26. Kopp J, Noah ME, Ruebben A, Merk HF, Pallua $\mathrm{N}$. Radical resection of giant congenital melanocytic nevus and reconstruction with Meek-graft covered Integra dermal template. Dermatol Surg 2003; 29(6):653-657.

27. Wolter TP, Noah ME, Pallua N. The use of Integra in an upper extremity avulsion injury. $\mathrm{Br}$ J Plast Surg 2005; 58(3):416-418.

28. Papp A, Haerma M. A collagen based dermal substitute and the modified Meek technique in extensive burns. Report of three cases. Burns 2003; 29(2):167-171.

29. Fitton AR, Drew $P$, Dickson WA. The use of a bilaminate artificial skin substitutes (Integra) in acute resurfacing of burns: an early experience. Br J Plast Surg 2001; 54(3):208-212.

30. Chou T-D, Chen S-L, Lee T-W, et al. Reconstruction of burn scar of the upper extremities with artificial skin. Plast Reconstr Surg 2001; 108(2):378-384.

31. Popescu S, Ghetu N, Grosu O, Nastasa M, Pieptu D. Integra ${ }^{T M}$ - a therapeutic alternative in reconstructive surgery, our first experience. Chirurgia 2007; 102(2):319-325. 